\title{
Safe to Sedate for Bronchoscopy despite Respiratory Failure
}

\author{
Pyng Lee $^{a}$ Praveen N. Mathur ${ }^{b}$ \\ a Department of Respiratory and Critical Care Medicine, Singapore General Hospital, Singapore, Singapore; \\ ${ }^{\mathrm{b}}$ Indiana University School of Medicine, Indianapolis, Ind., USA
}

In the study by Dreher et al. [1] published in this issue of Respiration, the authors sought to determine if sedation could be safely administered in patients with respiratory failure who required bronchoscopy. The study consisted of 2 groups of patients showing baseline hypoxemia with or without hypercapnia while breathing room air. Oxybuprocaine and conscious sedation comprising of midazolam alone or in combination with alfentanil were used. Contrary to recommendations [2] where transient apnea has been reported to occur when midazolam is combined with opioid (e.g. alfentanil), which further worsens hypoxia and carbon dioxide retention in patients with underlying respiratory failure [3] and therefore is contraindicated for routine use, Dreher et al. demonstrated that combination therapy led to halving the median dose of midazolam and better patient comfort without excessive complications or delay in recovery. Several limitations have been identified. Firstly, neither patient nor investigator was blinded to the drugs administered, which could lead to biases when reporting subjective scores. Secondly, the results were not only restricted to alfentanil, since all procedures were performed by an experienced bronchoscopist they could not be generalized to less skilful investigators. Median time and dose of midazolam for various bronchoscopic procedures were also not indicated in the study. Comparatively more transbronchial lung biopsies were performed in the midazolam group, and higher doses of midazolam might be required to obtund the cough reflex in order to facilitate performance of the procedure [4].
The safety observed with combined midazolam and alfentanil administration is confined to patients with stable respiratory failure undergoing basic bronchoscopic procedures. These results cannot be extended to advanced techniques such as endobronchial ultrasound needle aspiration for mediastinal staging, stenting or tumor debulking using electrosurgery or argon plasma coagulation, which can be lengthy and may require deeper sedation [5]. Notwithstanding that this is the first study demonstrating feasibility of sedation during bronchoscopy in patients with respiratory failure, it is noteworthy that bronchoscopy can be successfully performed using local anesthesia alone, complemented at times with music [6].

\section{References}

1 Dreher M, Ekkernkamp E, Storre JH, Kabitz H-J, Windisch W: Sedation during flexible bronchoscopy in patients with pre-existing respiratory failure: midazolam versus midazolam plus alfentanil. Respiration 2010;79:307-314.

2 British Thoracic Society guidelines on diagnostic flexible bronchoscopy. Thorax 2001;56:(suppl 1):i1-i21.

3 Crawford M, Pollock J, Anderson K, Glavin RJ, MacIntyre D, Vernon $\mathrm{D}$ : Comparison of midazolam with propofol for sedation in outpatient bronchoscopy. Br J Anaesth 1993;70:419-422.

4 Lee P, Mehta AC, Mathur PN: Management of complications from diagnostic and interventional bronchoscopy. Respirology 2009;14:940953.

5 Cohen NA, Stead SW: Moderate sedation for chest physicians. Chest 2008; 133:1489-1494

6 Triller N, Erzen D, Duh S, Petrinec Primozic M, Kosnik M: Music during bronchoscopic examination: the physiological effects. A randomized trial. Respiration 2006;73:95-99.

\section{KARGER}

Fax +41613061234 E-Mail karger@karger.ch www.karger.com
(C) 2010 S. Karger AG, Basel

0025-7931/10/0794-0276\$26.00/0

Accessible online at:

www.karger.com/res
Pyng Lee, MD

Department of Respiratory and Critical Care Medicine, Singapore General Hospital

Outram Road

Singapore 169608 (Singapore)

Tel. +65 6321 4700, Fax +65 6227 1736, E-Mail lee.pyng@sgh.com.sg 